\title{
Numerical study of nonlinear problems in the dynamics of thin-walled structural elements
}

\author{
Olim Kucharov ${ }^{1}$, Fozil Turaev ${ }^{1}$ Sergey Leonov ${ }^{2}$ and Kholida Komilova ${ }^{1}$, \\ ${ }^{1}$ Tashkent Institute of Irrigation and Agricultural Mechanization Engineers, Tashkent, Uzbekistan \\ ${ }^{2}$ National Technical University "Kharkiv Polytechnic Institute", Ukraine
}

\begin{abstract}
Mathematical model of the problem of vibration of thin-walled structural elements has been constructed based on Kirchhoff-Love theory. The problem is reduced, using the Bubnov-Galerkin method, to the solution of a set of nonlinear integro-differential Volterra type equations with weakly-singular kernels of relaxation. A numerical method based on the use of quadrature formulae being used for their solution. The influence of rheological parameters of the material on the values of critical velocity and amplitude-frequency characteristics of viscoelastic thin-walled structural elements is analyzed. It is shown that tacking account viscoelastic properties of the material of thin-walled structures lead to a decrease in the critical rate of gas flow.
\end{abstract}

\section{Introduction}

The theory of viscoelasticity is attracting more and more interest from researchers due to the widespread use of new materials in technology and traditional materials in specific conditions. Evidence of this is the publication of several articles [1-5]. Recently, much attention has been paid to studying the dynamics of essentially nonlinear viscoelastic mechanical systems [6-12], [26, 27].

The basic research trend consisted of preliminary reduction of problems using variational methods of a continuous structure to a system with one-or-two degrees of freedom, which was then analyzed either numerically or using analytical methods of nonlinear mechanics. The main attention was paid to determining the qualitative effects caused by the impact of nonlinear forces.

The problems of bending, strength and dynamics of viscoelastic thin-walled structural elements were studied by B.A. Khudayarov and his students [13-25], [28-43].

This work is devoted to mathematical modelling and creating an algorithm for the numerical solution of dynamic problems of hereditary deformable systems.

Consider the dynamics of a thin-walled structure accounting for hereditary properties of the material according to the generalized Timoshenko theory in a geometrically nonlinear statement.

Under accepted assumptions, the mathematical model of this problem relative to the functions $w=w(x, y, t), \psi_{x}=\psi_{x}(x, y, t), \psi_{y}=\psi_{y}(x, y, t)$ and $\Phi=\Phi(x, y, t)$ is described by the equation under corresponding boundary and initial conditions: 


$$
\begin{gathered}
\frac{K^{2} E}{2(1+\mu)}\left(1-R^{*}\right)\left(\nabla^{2} w+\frac{\partial \psi_{X}}{\partial x}+\frac{\partial \psi_{y}}{\partial y}\right)+L(w, \Phi)-\frac{x p_{\infty}}{\mathrm{h} V_{\infty}}\left(\frac{\partial w}{\partial t}+V \frac{\partial w}{\partial x}\right)-\rho \frac{\partial^{2} w}{\partial t^{2}}=0 \\
\frac{D}{h}\left(1-R^{*}\right)\left[\frac{\partial^{2} \psi_{X}}{\partial x^{2}}+\frac{1}{2}(1+\mu) \frac{\partial^{2} \psi_{y}}{\partial x \partial y}+\frac{1}{2}(1-\mu) \frac{\partial^{2} \psi_{X}}{\partial y^{2}}\right]- \\
\frac{K^{2} E}{2(1+\mu)}\left(1-R^{*}\right)\left(\frac{\partial w}{\partial x}+\psi_{X}\right)-\rho \frac{h^{2}}{12} \frac{\partial^{2} \psi_{X}}{\partial t^{2}}=0,(x \leftrightarrow y) \\
\frac{1}{E} \nabla^{4} \Phi=-\frac{1}{2} 1-R^{*} L W, W
\end{gathered}
$$

\section{Methods}

Let the thin-walled structure be supported by hinges on all edges. Satisfying the boundary conditions of the problem, we choose expressions for functions $w=w(x, y, t)$, $\psi_{x}=\psi_{x}(x, y, t), \psi_{y}=\psi_{y}(x, y, t)$ based on the polynomial approximation in the following form:

$$
\begin{aligned}
w(x, y, t) & =\sum_{n=1} \sum_{m=1}^{N} w_{\mathrm{nm}}(t) \sin \frac{n \pi x}{a} \sin \frac{m \pi y}{b} \\
\psi_{x}(x, y, t) & =\sum_{n=1} \sum_{m=1} \psi_{\mathrm{xnm}}(t) \cos \frac{n \pi x}{a} \sin \frac{m \pi y}{b} \\
\psi_{y}(x, y, t) & =\sum_{n=1} \sum_{m=1} \psi_{\mathrm{ynm}}(t) \sin \frac{n \pi x}{a} \cos \frac{m \pi y}{b}
\end{aligned}
$$

Substituting the first expression (2) into the fourth equation of system (1) and equating in both sides of this equation the coefficients for the same harmonics of trigonometric functions, we find the force function:

$$
\begin{aligned}
& \Phi(x, y, t)=E \sum_{i, j=1 r, s=1}^{N} \sum^{M}\left(1-R^{*}\right) w_{\mathrm{ir}} W_{\mathrm{js}}\left[C_{\mathrm{irjs}} \cos \frac{(i+j) \pi x}{a} \cos \frac{(r+s) \pi y}{b}+\right. \\
& +A_{\mathrm{irjs}} \cos \frac{(i+j) \pi x}{a} \cos \frac{(r-s) \pi y}{b}+D_{\mathrm{irjs}} \cos \frac{(i-j) \pi x}{a} \cos \frac{(r+s) \pi y}{b}+ \\
& \left.+B_{\mathrm{irjs}} \cos \frac{(\stackrel{i}{i} \underset{j}{)}) \pi x}{a} \cos \frac{(r-\stackrel{b}{s}) \pi y}{b}\right]
\end{aligned}
$$

where 


$$
\begin{gathered}
C_{\text {irjs }}=-\frac{\lambda^{2} \text { ir }(\text { ir }-\mathrm{js})}{4\left[(i+j)^{2}+\lambda^{2}(r+s)^{2}\right]^{2}}, \quad A_{\text {irjs }}=\frac{\lambda^{2} \text { ir }(\mathrm{ir}+\mathrm{js})}{4\left[(i+j)^{2}+\lambda^{2}(r-s)^{2}\right]^{2}}, \\
D_{\text {irjs }}=\frac{\lambda^{2} \operatorname{ir}(\mathrm{ir}+\mathrm{js})}{4\left[(i-j)^{2}+\lambda^{2}(r+s)^{2}\right]^{2}}, \quad B_{\text {irjs }}=-\frac{\lambda^{2} \operatorname{ir}(\mathrm{ir}-\mathrm{js})}{4\left[(i-j)^{2}+\lambda^{2}(r-s)^{2}\right]^{2}}, \lambda=\frac{a}{b}
\end{gathered}
$$

Substituting (2) and (3) into the first three equations of (1) and performing the BubnovGalerkin procedure with respect to $w_{k l}, \psi_{x k l}, \psi_{y k l}$, we obtain

$$
\begin{aligned}
& \rho \ddot{w} \mathrm{kl}+\frac{\partial \varphi_{\infty}}{V_{\infty} h} \dot{w}_{\mathrm{kl}}+\frac{K^{2} E \pi^{2}}{2(1+\mu) b^{2}}\left[\left(\frac{k}{\lambda}\right)^{2}+l^{2}\right]\left(1-R^{*}\right) w_{\mathrm{kl}}+ \\
& +\frac{2 x \varphi_{\infty} V}{\operatorname{ahV}_{\infty}} \sum_{n=1}^{N} n\left(\gamma_{n+k}-\gamma_{n-k}\right) w_{\mathrm{nl}}+ \\
& +\frac{K^{2} E \pi}{2(1+\mu) b}\left(1-R^{*}\right)\left[\left(\frac{k}{\lambda}\right) \psi_{\mathrm{xkl}}+l \psi_{\mathrm{ykl}}\right]+ \\
& +\frac{E \pi^{2}}{b^{4}} \sum_{n, i, j=1}^{N} \sum_{m, r, S=1}^{M} a_{\mathrm{klnmirjs}} w_{\mathrm{nm}}\left(1-R^{*}\right) w_{\mathrm{ir}} w_{\mathrm{js}}=0, \\
& \rho h^{2} \ddot{\psi}_{\mathrm{xkl}}+\frac{\mathrm{Eh}^{2}}{2\left(1-\mu^{2}\right)}\left[\frac{2 \pi^{2} k^{2}}{a^{2}}+\frac{\pi^{2} I^{2}}{b^{2}}(1-\mu)+\frac{12 K^{2}}{h^{2}}(1-\mu)\right]\left(1-R^{*}\right) \psi_{\mathrm{xkl}}+ \\
& +\frac{E \pi^{2} h^{2} \mathrm{kl}}{2 \mathrm{ab}(1-\mu)}(1-R) \psi_{\mathrm{ykl}}+\frac{6 K^{2} E \pi k}{a(1+\mu)}(1-R) w_{\mathrm{kl}}=0, \\
& \rho h^{2} \ddot{\psi}_{\mathrm{xkl}}+\frac{\mathrm{Eh}^{2}}{2\left(1-\mu^{2}\right)}\left[\frac{2 \pi^{2} k^{2}}{a^{2}}+\frac{\pi^{2} l^{2}}{b^{2}}(1-\mu)+\frac{12 K^{2}}{h^{2}}(1-\mu)\right]\left(1-R^{*}\right) \psi_{\mathrm{xkl}}+ \\
& +\frac{E \pi^{2} h^{2} \mathrm{kl}}{2 \mathrm{ab}(1-\mu)}\left(1-R^{*}\right) \psi_{\mathrm{ykl}}+\frac{6 K^{2} E \pi k}{a(1+\mu)}\left(1-R^{*}\right) w_{\mathrm{kl}}=0 \text {, } \\
& \rho h^{2} \ddot{\psi}_{\mathrm{ykl}}+\frac{\mathrm{Eh}^{2}}{2\left(1-\mu^{2}\right)}\left[\frac{2 \pi^{2} I^{2}}{b^{2}}+\frac{\pi^{2} k^{2}}{a^{2}}(1-\mu)+\frac{12 K^{2}}{\mathrm{bh}}(1-\mu)\right]\left(1-R^{*}\right) \psi_{\mathrm{ykl}}+ \\
& +\frac{E \pi^{2} h^{2} \mathrm{kl}}{2 \mathrm{ab}(1-\mu)}\left(1-R^{*}\right) \psi_{\mathrm{xkl}}+\frac{6 K^{2} E \pi l}{b(1+\mu)}\left(1-R^{*}\right) w_{\mathrm{kl}}=0 \\
& w_{\mathrm{kl}}(0)=w_{0 \mathrm{kl}}, \dot{w}_{\mathrm{kl}}(0)=\tilde{w}_{0 \mathrm{kl}}, \psi_{\mathrm{xkl}}(0)=\psi_{x 0 \mathrm{kl}}, \dot{\psi}_{\mathrm{xkl}}(0)=\tilde{\psi}_{x 0 \mathrm{kl}} \text {, }
\end{aligned}
$$




$$
\psi_{\mathrm{ykl}}(0)=\psi_{y 0 \mathrm{kl}}, \dot{\psi}_{\mathrm{ykl}}(0)=\tilde{\psi}_{y 0 \mathrm{kl}}, k=1,2, \ldots, N ; l=1,2, \ldots, M
$$

where $\gamma_{k}=\frac{\alpha_{k}}{k}$; coefficient $\alpha_{k}=1$, if $k$ is odd, if $k$ is even or equal to 0 , then $\alpha_{k}=0 ; a_{k l n m i r j s}$ are the dimensionless coefficients.

Introducing into the system (4) dimensionless quantities

$$
\frac{w_{\mathrm{kl}}}{h}, \frac{V_{\infty} t}{a}, \frac{\mathrm{aR}(t)}{V_{\infty}}
$$

while maintaining the previous notation relative to the dimensionless unknowns $w_{k l}=$ $w_{k l}(t), \psi_{x k l}=\psi_{x k l}(t)$ and $\psi_{y k l}=\psi_{y k l}(t)$ we obtain

$$
\begin{aligned}
& \ddot{w} \mathrm{kl}+M_{p} \mu \partial \delta\left\{\dot{w}_{\mathrm{kl}}+\frac{K^{2} M_{E} \pi^{2} \lambda^{2}}{2(1+\mu)}\left[\left(\frac{k}{\lambda}\right)^{2}+l^{2}\right]\left(1-R^{*}\right) w_{\mathrm{kl}}+\right. \\
& +2 M M_{p} \rightsquigarrow 2 \delta \sum_{n=1}^{N} n\left(\gamma_{n+k}-\gamma_{n-k}\right) w_{\mathrm{nl}}+ \\
& +\frac{K^{2} M_{E} \pi \lambda^{2} \delta}{2(1+\mu)}\left(1-R^{*}\right)\left[\left(\frac{k}{\lambda}\right) \psi_{\mathrm{xkl}}+l \psi_{\mathrm{ykl}}\right]+ \\
& \frac{p^{2} M_{E} \lambda^{2}}{\delta^{2}} \sum_{n, i, j=1}^{N} \sum_{m, r, S=1}^{M} a_{\text {klnmirjs }} W_{\mathrm{nm}}\left(1-R^{*}\right) w_{\mathrm{ir}} W_{\mathrm{js}}=0 \\
& \ddot{\psi}_{\mathrm{xkl}}+\frac{M_{E}}{2\left(1-\mu^{2}\right)}\left[2 \pi^{2} k^{2}+\pi^{2} \lambda^{2}(1-\mu) l^{2}+12 K^{2} \lambda^{2} \delta^{2}(1-\mu)\right]\left(1-R^{*}\right) \psi_{\mathrm{xkl}}+ \\
& +\frac{M_{E} \pi^{2} \lambda}{2(1-\mu)} \mathrm{kl}\left(1-R^{*}\right) \psi_{\mathrm{ykl}}+\frac{6 K^{2} M_{E} \pi \lambda \delta}{1+\mu} k\left(1-R^{*}\right) w_{\mathrm{kl}}=0 \\
& \ddot{\psi}_{\mathrm{ykl}}+\frac{M_{E}}{2\left(1-\mu^{2}\right)}\left[2 \pi^{2} \lambda^{2} l^{2}+\pi^{2}(1-\mu) k^{2}+12 K^{2} \lambda^{2} \delta^{2}(1-\mu)\right]\left(1-R^{*}\right) \psi_{\mathrm{ykl}}+ \\
& +\frac{M_{E} \pi^{2} \lambda}{2(1-\mu)} \mathrm{kl}\left(1-R^{*}\right) \psi_{\mathrm{xkl}}+\frac{6 K^{2} M_{E} \pi \lambda^{2} \delta}{1+\mu} l\left(1-R^{*}\right) w_{\mathrm{kl}}=0, \\
& w_{\mathrm{kl}}(0)=w_{0 \mathrm{kl}}, \dot{w}_{\mathrm{kl}}(0)=\tilde{w}_{0 \mathrm{kl}}, \psi_{\mathrm{xkl}}(0)=\psi_{x 0 \mathrm{kl}}, \dot{\psi}_{\mathrm{xkl}}(0)=\tilde{\psi}_{x 0 \mathrm{kl}} \text {, } \\
& \psi_{\mathrm{ykl}}(0)=\psi_{y 0 \mathrm{kl}}, \quad \dot{\psi}_{\mathrm{ykl}}(0)=\tilde{\psi}_{y 0 \mathrm{kl}}, k=1,2, \ldots, N ; l=1,2, \ldots, M,
\end{aligned}
$$

where $\delta=\frac{b}{h}, M_{p}=\frac{p_{\infty}}{\rho V_{\infty}^{2}}, M_{E}=\frac{E}{\rho V_{\infty}^{2}}, M^{*}=\frac{V}{V_{\infty}}$. 


\section{Results and discussion}

Here, the upper exact limit of the velocity set $\{\mathrm{V}\}$ is chosen as a criterion for determining the critical rate of gas flow; it ensures the convergence of the Bubnov-Galerkin expansion (2) for all $t=0$ (Fig. 1), i.e. the following condition is satisfied

$$
w(x, y, t)=\sum_{n=1} \sum_{m=1}^{M} w_{\mathrm{nm}}(t) \varphi_{\mathrm{nm}}(x, y)<1
$$

At $V>V_{c r}$, the oscillatory motion occurs at rapidly increasing amplitudes and can lead to structure destruction (Fig. 2); at $V<V_{c r}$, the vibration amplitude damps (Fig. 3). Note that at $V>V_{c r}$, the expansion (2) diverges.

Here, the initial data are taken as: $A=0.0104, \alpha=0.1, \beta=0.0166$ (material KAST-B $90^{0}$ ), $M_{E}=4.71, M_{P}=0.003, V=1900 \mathrm{~m} / \mathrm{s}$ (Fig.1), $2300 \mathrm{~m} / \mathrm{s}$ (Fig.2), $600 \mathrm{~m} / \mathrm{s}$ (Fig.3).

The results of calculating a thin-walled structure with the hereditary properties of a material streamlined by a supersonic gas flow at $V<V_{c r}$ are presented in Figs. 4 - 6. For this purpose, the gas flow velocity is assumed to be $800 \mathrm{~m} / \mathrm{s}$ when studying the behaviour of a thin-walled structure with various physical and geometric parameters. Unless other data are specified, the following values are taken as the initial ones: $A=0.0104, \alpha=0.1$, $\beta=0.0166$ (material KAST-B $90^{\circ}$ ), $M_{E}=4.71, M_{P}=0.003$.

Figs. 4 - 6 show the dependences of functions $w, u$ and $v$, respectively, on time in the midpoint of a thin-walled structure not considering $(A=0$ - curve 1$)$ and considering the hereditary properties of the material $\left(A=0.0099, \alpha=0.1, \beta=0.001\right.$ (material) KAST-B $0^{0}$ - curve 2; $A=0.0208, \alpha=0.1, \beta=0.0166$ (material KAST-B $45^{0}$ ) - curve 3 ).

As seen from Fig. 4, an account for hereditary properties of the material leads to oscillatory process attenuation. Although the solutions to problems with and without account for hereditary properties of the material in the initial period of time differ little from each other, over time, the hereditary properties of the material have a significant impact.

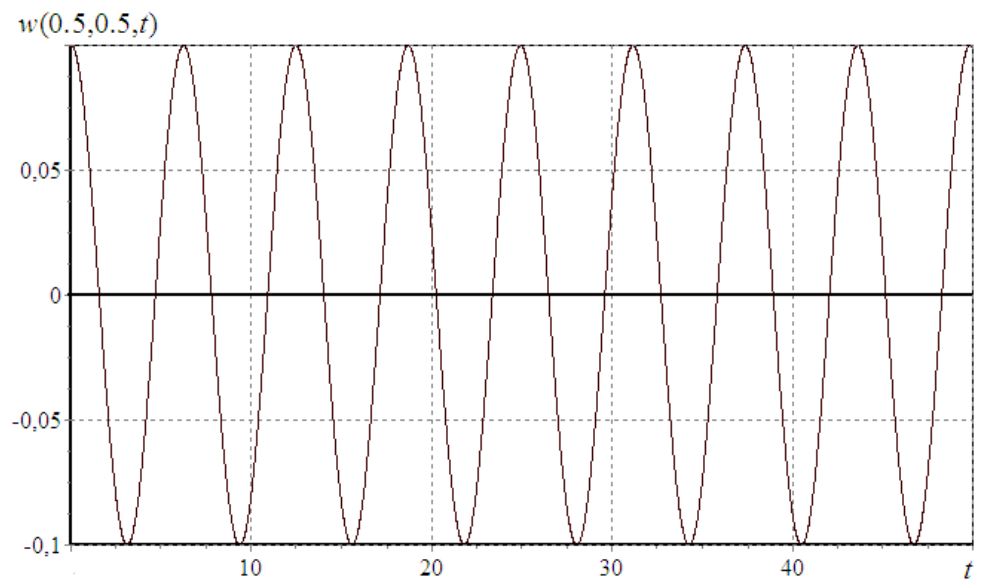

Fig.1. Deflection dependence on time 


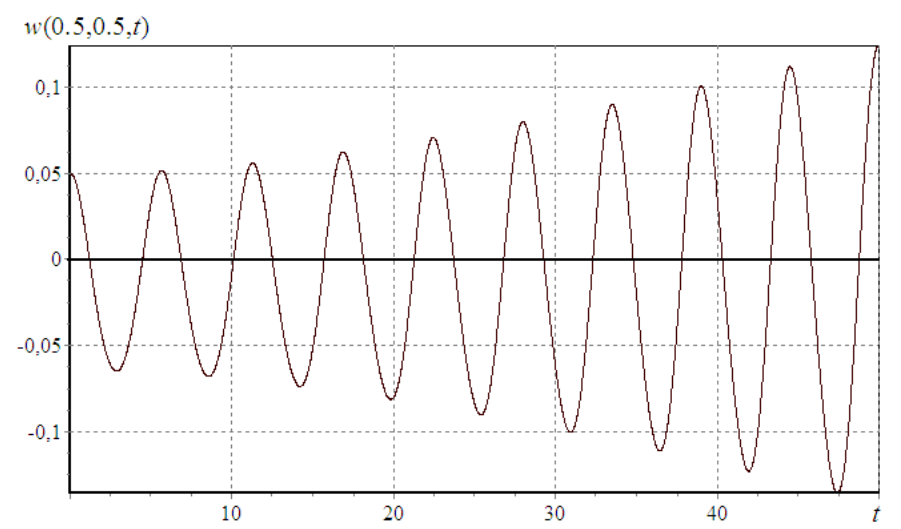

Fig.2. Deflection dependence on time

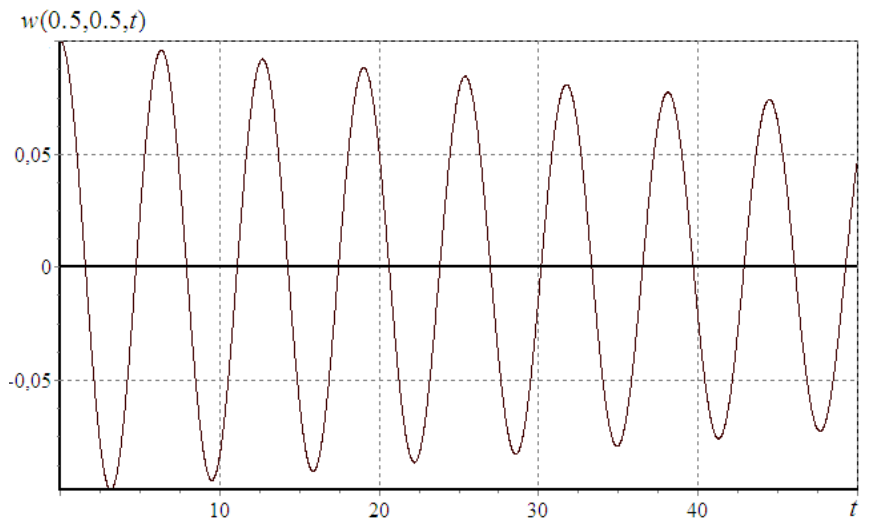

Fig.3. Deflection dependence on time

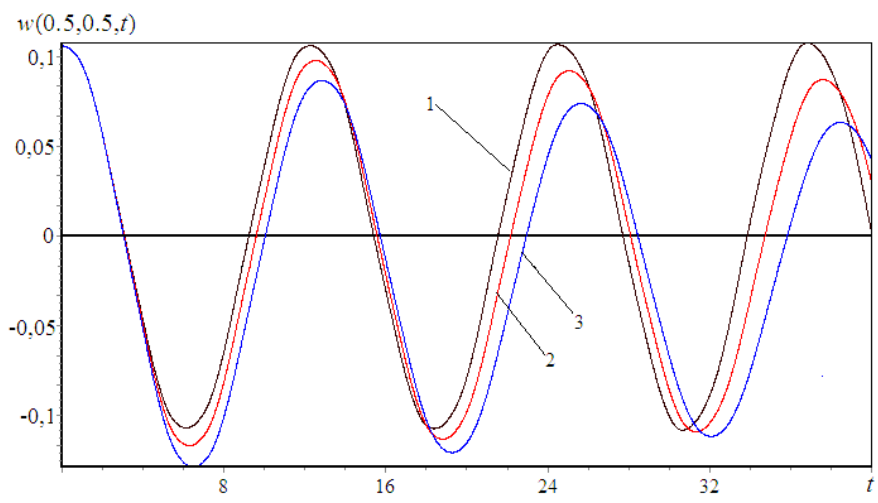

Fig.4. Function $w$ dependence on time: $A=0(1)$; KAST-B $0^{0}(2)$; KAST-B $45^{0}$ (3) 


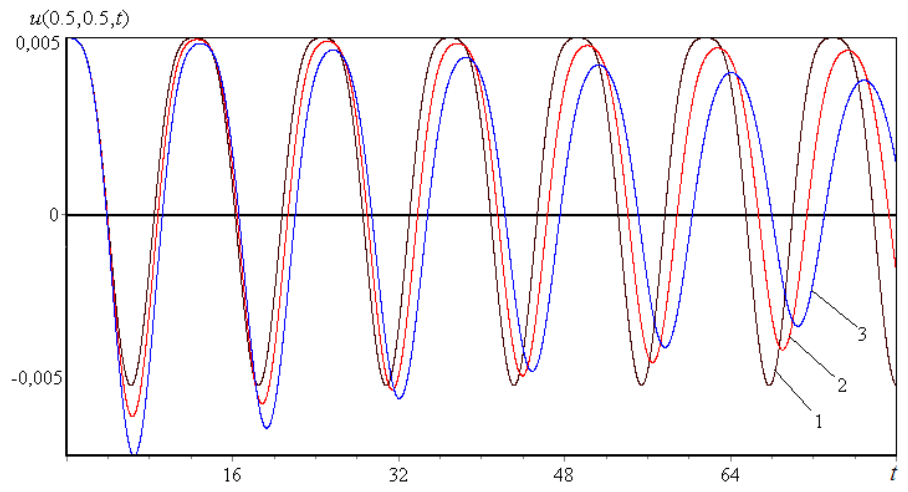

Fig.5. Function $u$ dependence on time: $A=0$ (1); KAST-B $0^{0}(2)$; KAST-B $45^{\circ}$ (3)

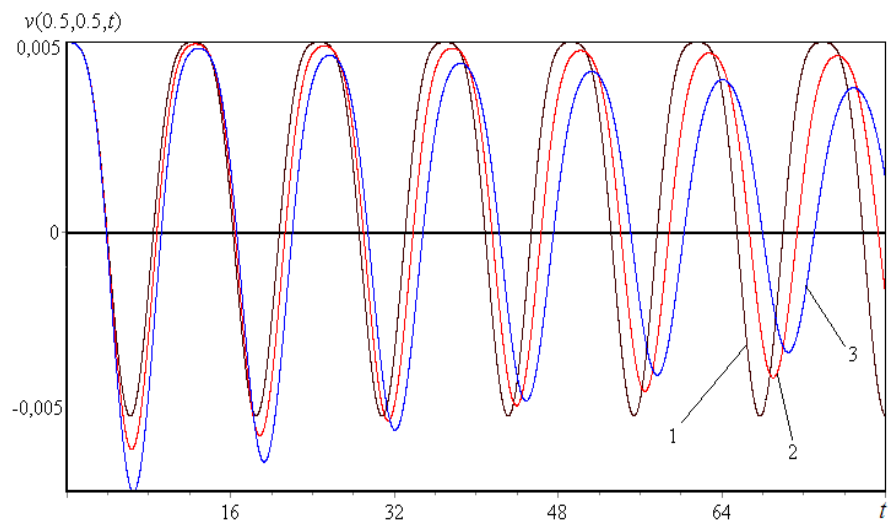

Fig.6. Function $v$ dependence on time: $A=0(1)$; KAST-B $0^{0}(2)$; KAST-B $45^{0}(3)$

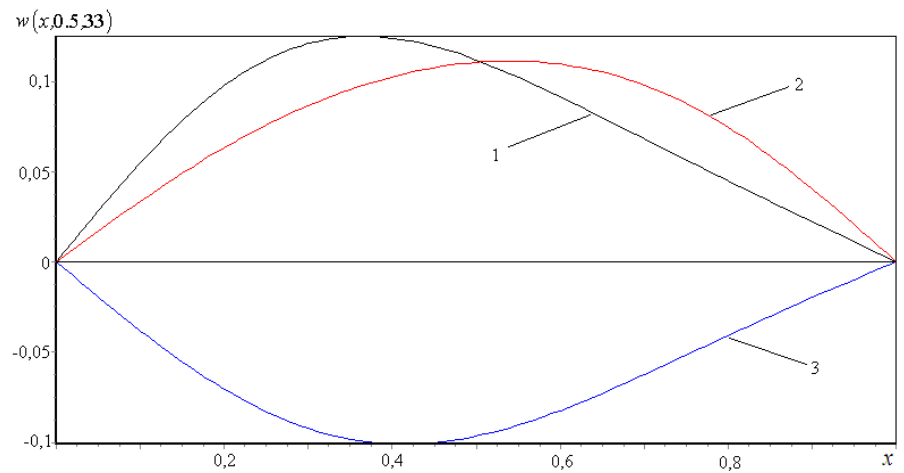

Fig.7. Comparison of the modes of vibrations at $t=33$ : $A=0(1)$; KAST-B $0^{0}(2)$; KAST-B $45^{0}(3)$

Figure 7 shows the change in the function $w$ along the length of a thin-walled structure at $t=33$. Consideration of hereditary properties shows a decrease in the values of maximum deflections.

\section{Conclusions}

Mathematical models of the dynamics problems of thin-walled structural elements are built considering hereditary properties of the material. The basic resolving integro-differential 
equations of dynamic problems of the hereditary theory are obtained using the BubnovGalerkin method.

The effect of various properties of structure material on the values of critical velocity and amplitude-frequency characteristics is analyzed.

An analysis of the results revealed some new effects:

- an account for hereditary properties of the material of thin-walled structures leads to a decrease in the critical rate of gas flow;

- an account for geometrical nonlinearity leads to an increase in critical velocity;

- an account for aerodynamic nonlinearity does not significantly change the value of critical velocity.

\section{References}

1. Dmitriev V G, Egorova O V, Zhavoronok S I et al, Investigation of Buckling Behavior for Thin-Walled Bearing Aircraft Structural Elements with Cutouts by Means of Numerical Simulation Russ. Aeronaut 61, pp 165-174. https://doi.org/10.3103/S1068799818020034. (2018).

2. Abrosimov N A, Numerical modeling of nonlinear deformation and buckling of composite plate-shell structures under pulsed loading Mech Compos Mater 35 pp 495-506. https://doi.org/10.1007/BF02259471.(1999)

3. Dowell E H, Edwards J and Strganac T W,Nonlinear aeroelasticity J.Aircraft 40 (5) pp 857-874, 10.2514/2.6876, (2003)

4. Dowell E H, Edwards J and Strganac T W, Nonlinear aeroelasticity J.Aircraft 40 (5) $857-874,10.2514 / 2.6876$. (2003)

5. Vasconcellos R M G, Abdelkefi A, Marques F D and Hajj M R, Representation and analysis of control surface free play nonlinearity, J. Fluids Struct. 31 pp 79-91, 10.1016/j.- jfluidstructs. 2012. 02.00391 (2012)

6. Thiago de Sales P, Daniel Pereira A, Flávio Marques D and Domingos Rade A 2019 Modeling and dynamic characterization of nonlinear non-smooth aeroviscoelastic systems Mechanical Systems and Signal Processing 116 pp 900-915. https: //doi.org/10.1016/j .ymssp .2018.07.003. (2019)

7. Nobuyuki SHIMIZU and Wei ZHANG, Fractional Calculus Approach to Dynamic Problems of Viscoelastic Materials, JSME International Journal Series C Mechanical Systems, Machine Elements and Manufacturing 42, (4) pp 825-837 https://doi.org/10.1299/jsmec.42.825, (1999).

8. Mirsaidov M. Using linear hereditary theory of viscoelasticity by dynamic calculation of earth structures Bases, Foundations and Soil Mechanics 6 pp 30-34. (2012)

9. Mirsaidov M and Sultanov T, Use of linear hereditary theory of viscoelasticity for dynamic analysis of earth structures, Soil Mechanics \& Foundation Engineering. 49 (6) pp 250-256. DOI: 10.1007/s11204-013-9198-8, (2013)

10. Badalov F B, Khudayarov B A and Abdukarimov A, Effect of the hereditary kernel on the solution of linear and nonlinear dynamic problems of hereditary deformable systems, Journal of Machinery Manufacture and Reliability 36 pp 328-335. https://doi.org/10.3103/S1052618807040048. ( 2013)

11. Badalov F B Methods for Solving Integral and Integro-differential Equations of the Hereditary Theory of Viscoelasticity (Tashkent: Mekhnat).(1987)

12. Khudayarov B.A., and Turaev F.Zh. Mathematical Simulation of Nonlinear Oscillations of Viscoelastic Pipelines Conveying Fluid, Applied Mathematical Modelling 66 pp 662-679, https://doi.org/10.1016/j.apm.2018.10.008. (2019). 
13. Khudayarov B A, Komilova $\mathrm{Kh} \mathrm{M}$ and Turaev $\mathrm{F}$ Zh Dynamic analysis of the suspended composite pipelines conveying pulsating fluid Journal of Natural Gas Science and Engineering 75 pp 103148. https://doi.org/10.1016/j.jngse.2020.103148. (2020).

14. Khudayarov B A and Turaev F Nonlinear vibrations of fluid transporting pipelines on a viscoelastic foundation Magazine of Civil Engineering 86 (2) pp 30-45. DOI: 10.18720/MCE.86.4. (2019)

15. Khudayarov B A, Komilova $\mathrm{Kh} \mathrm{M}$ and Turaev $\mathrm{F} \mathrm{Zh}$, The effect of two-parameter Pasternak foundations on the oscillations of composite pipelines conveying gascontaining fluids International Journal of Pressure Vessels and Piping 176 pp 103946. https://doi.org/10.1016/j.ijpvp.2019.103946.( 2019)

16. Khudayarov B A and Turaev F Zh Nonlinear supersonic flutter for the viscoelastic orthotropic cylindrical shells in supersonic flow Aerospace Science and Technology 84 120-130. doi: 10.1016/j.ast.2018.08.044.(2019).

17. Khudayarov B A and Komilova Kh M, Vibration and dynamic stability of composite pipelines conveying a two-phase fluid flows Engineering Failure Analysis 104 pp.500512.

18. Khudayarov B A, Komilova Kh M and Turaev F Zh, Numerical Simulation of Vibration of Composite Pipelines Conveying Pulsating Fluid International Journal of Applied Mechanics 11 https://doi.org/10.1142/S175882511950090X.(2019) 1950090.

19. Khudayarov B A, Komilova Kh M, Turaev F Zh and Aliyarov J A, Numerical simulation of vibration of composite pipelines conveying fluids with account for lumped masses, International Journal of Pressure Vessels and Piping 179104034. https://doi.org/10.1016/j.ijpvp.2019.104034. (2020)

20. Khudayarov B A, and Komilova $\mathrm{Kh} \mathrm{M}$, Numerical modeling of vibrations of viscoelastic pipelines conveying two-phase slug flow Vestnik Tomskogo Gosudarstvennogo Universiteta. Matematika i Mekhanika 61 pp 95-110. DOI: https://doi.org/10.17223/19988621/61/9. (2019)

21. Khudayarov B A, and Turaev F Zh Numerical simulation of nonlinear oscillations of a viscoelastic pipeline with fluid, Vestn. Tom. Gos. un-ta. Matematika i mekhanika 5 (43) pp 90-98. DOI:10.17223/19988621/43/10. (2016)

22. Khudayarov B A, Modeling of supersonic nonlinear flutter of plates on a visco-elastic foundation. Advances in aircraft and spacecraft science 6 (3) pp 257-272. https://doi.org/10.12989/aas.2019.6.3.257. (2019)

23. Khudayarov B, Turaev F and Kucharov O, Computer simulation of oscillatory processes of viscoelastic elements of thin-walled structures in a gas flow, E3S Web of Conferences 97 06008. https://doi.org/10.1051/e3sconf/20199706008,(2019)

24. Khudayarov B.A, Ruzmetov K.Sh, Turaev F.Zh, Vaxobov V.V, Hidoyatova M A, Mirzaev S.S and Abdikarimov R. Numerical modeling of nonlinear vibrations of viscoelastic shallow shells, Engineering Solid Mechanics 8 (3) pp 187-300. (2020).

25. Filippov, I. G.and Kudainazarov, K, Refinement of equations describing longitudinalradial vibrations of a circular cylindrical viscoelastic shell. Soviet Applied Mechanics, 26 (2), pp 161-168. doi:10.1007/bf00887110.(1990).

26. Filippov, I. G. \&Kudainazarov, K. General transverse vibrations equations for a circular cylindrical viscoelastic shell. Soviet Applied Mechanics, 26 (4), pp 351357. doi:10.1007/bf00887127. (1990).

27. Khudayarov B A, Komilova K M and Turaev F Z, Numerical study of the effect of viscoelastic properties of the material and bases on vibration fatigue of pipelines conveying pulsating fluid flow. Engineering Failure Analysis., 115,104635, (2020). 
28. Khudayarov B A, Turayev F, Zhuvonov Q, Vahabov V, Kucharov O and Kholturaev $\mathrm{Kh}$, Oscillation modeling of viscoelastic elements of thin-walled structures. IOP Conference Series: Materials Science and Engineering.. 883(1),012188, (2020).

29. Turaev F, Khudayarov B, Kucharov O, Rakhmatullaev A, Zhuvonov K and Gulomov O Dynamic stability of thin-walled structure elements considering hereditary and inhomogeneous properties of the material. IOP Conference Series: Materials Science and Engineering.. 883(1),012187. (2020).

30. Khudayarov B, Turaev F, Vakhobov V, Gulamov O and Shodiyev S, Dynamic stability and vibrations of thin-walled structures considering heredity properties of the material, IOP Conference Series: Materials Science and Engineering. 2020. 869(5),052021. (2020).

31. Khudayarov B A, Komilova Kh M and Turaev F Zh, Dynamic analysis of the suspended composite pipelines conveying pulsating fluid, Journal of Natural Gas Science and Engineering 75 103148. https://doi.org/10.1016/j.jngse.2020.103148 (2020)

32. Khudayarov B A, Komilova Kh M, Turaev F Zh and Aliyarov J A Numerical simulation of vibration of composite pipelines conveying fluids with account for lumped masses, International Journal of Pressure Vessels and Piping 179104034. https://doi.org/10.1016/j.ijpvp.2019.104034 (2020).

33. Khudayarov B A, Ruzmetov K Sh, Turaev F Zh, Vaxobov V V, Hidoyatova M A, Mirzaev S S and Abdikarimov R Numerical modeling of nonlinear vibrations of viscoelastic shallow shells Engineering Solid Mechanics 8 (3) pp 199-204.( 2020)

34. Khudayarov B A, Komilova Kh M and Turaev F Zh Numerical Simulation of Vibration of Composite Pipelines Conveying Pulsating Fluid International Journal of Applied Mechanics 11 (9) 1950090. https://doi.org/10.1142/S175882511950090X. (2019).

35. Khudayarov B, Turaev F and Kucharov O, Computer simulation of oscillatory processes of viscoelastic elements of thin-walled structures in a gas flow, E3S Web of Conferences 97 06008. https://doi.org/10.1051/e3sconf/20199706008. (2019)

36. Khudayarov B A and Turaev F Zh Nonlinear vibrations of fluid transporting pipelines on a viscoelastic foundation Magazine of Civil Engineering 86 (2).. pp. 30-45. DOI: 10.18720/MCE.86.4.( 2019).

37. Khudayarov B A and Turaev F Zh Nonlinear supersonic flutter for the viscoelastic orthotropic cylindrical shells in supersonic flow Aerospace Science and Technology 84 pp 120-130. doi: 10.1016/j.ast.2018.08.044. (2019)

38. Khudayarov B A, Flutter of a viscoelastic plate in a supersonic gas flow. International Applied Mechanics. 46 (4), pp 455-460.( 2010).

39. Khudayarov B A and Bandurin N G, Numerical investigation of nonlinear vibrations of viscoelastic plates and cylindrical panels in a gas flow. Journal of Applied Mechanics and Technical Physics. 48 (2), pp. 279-284.(2007)

40. Khudayarov B A, Flutter analysis of viscoelastic sandwich plate in supersonic flow. American Society of Mechanical Engineers, Applied Mechanics Division, AMD 256,. pp 11-17, (2005).

41. Khudayarov B A. Numerical analysis of the nonlinear flutter of viscoelastic plates. International Applied Mechanics. 41 (5), pp. 538-542.( 2005)

42. Khudayarov B A, Behavior of viscoelastic three-layered structures in a gas flow. Problems of machine building and reliability of machines.. (6), c. 87-90.( 2004)

43. Abdullayev, A.A., Ergashev, T.G. Poincare-tricomi problem for the equation of a mixed elliptico-hyperbolic type of second kind. Vestnik Tomskogo Gosudarstvennogo Universiteta, Matematika i Mekhanika, (65), pp 5-21, DOI 10.17223/19988621/65/1. (2020) 